\title{
The influence of microcrack density on the elastic and fracture mechanical properties of Stripa granite
}

\author{
Ove Alm and Lise-Lotte Jaktlund
}

Division of Rock Mechanics, Luleå University of Technology, S-951 87 Luleå (Sweden)

Kou Shaoquan

Institute of Mechanics, Academia Sinica, Beijing (People's Republic of China)

\begin{abstract}
Alm, O., Jaktlund, L.-L. and Kou, S., 1985. The influence of microcrack density on the elastic and fracture mechanical properties of Stripa granite. Phys. Earth Planet. Inter., 40: 161-179.

Microcracks can have a strong influence on the elastic and fracture mechanical properties of rocks if they are numerous, or if they are orientated in unfavourable directions in anisotropic rocks in particular. This paper presents results from a great number of mechanical tests on Stripa granite containing various amounts of microcracks. Variations in the microcrack density were obtained by shock-heating the rock at different temperatures in the range $100-600^{\circ} \mathrm{C}$ for $3 \mathrm{~h}$.

The results presented are obtained from sound velocity measurements, uniaxial compression tests, Brazilian tests and three-point bending tests. The density of microcracks in the heated rock is studied by means of optical microscopy, SEM and differential strain analysis (DSA).

Some of the calculated parameteres show a maximum value for specimens heat-treated at about $100^{\circ} \mathrm{C}$. The tensile strength is, for instance, substantially higher for specimens shock-heated at $100^{\circ} \mathrm{C}$ than for non-heated ones. Another striking feature is the initial decrease of the diameter observed in specimens heat-treated at $600^{\circ} \mathrm{C}$ when loaded in uniaxial compression. Both optical microscopy and DSA experiments reveal a large increase in microcracking when the heat-treatment temperature exceeds $300^{\circ} \mathrm{C}$.
\end{abstract}

\section{Introduction}

Almost all rocks contain some porosity, even though the volume content of cracks and pores can vary considerably, from several tens of per cent to fractions of a per cent. The shape of cracks and pores varies from one rock to another. Cavities tend to be more irregular and equidimensional in high porosity rocks compared to low porosity ones. On the whole we see more flat cracks in low porosity rocks.

Even small cracks can substantially influence the physical properties of rocks. A literature survey reveals a great number of papers dealing with different methods of characterizing microcracks, for example, Sprunt and Brace (1974), Simmons et al. (1974), Simmons and Richter (1976), Richter and Simmons (1977), Siegfried and Simmons (1978), Montoto et al. (1980), Montoto (1982) and Alm et al. (1983). Some papers treat the effect of microcracks on different physical properties of rocks (e.g., Walsh and Brace (1966), Cooper and Simmons (1977), Feves et al. (1977) and Johnson et al. (1978), but surprisingly few discuss the influence of microcracks on the mechanical properties. Small cracks can propagate and may eventually cause instabilities in large underground constructions (see Finnie et al., 1979). Microcracks may also play an important role as a weakening mechanism in rocks in connection with earthquakes and other large scale movements in the Earth's crust. Furthermore, exploration of geother- 
mal systems are based on rock properties that are controlled by microcracks.

In this paper we report results from mechanical testing of Stripa granite containing various amounts of microcracks. The values of the mechanical parameters are dependent on the density of microcavities in the rock. Homand-Étienne and Houpert (1982) recently published results from an investigation which in part dealt with the same problem.

\section{Experiment}

We have conducted a large number of different mechanical tests on Stripa granite containing various amounts of microcracks to elucidate their effect on the mechanical properties of this rock. The results discussed in this paper are extracted from this vast amount of data. All our results and a detailed description of the experimental and data reduction procedures are to be found in a report by Kou and Alm (1985a). Consequently, we restrict ourselves here to giving a few concise comments on these procedures, just enough to avoid confusion or misunderstandings.

Virtually any kind of mechanical test is sensitive to the density of microcracks in the test material, but the sensitivity varies from one method to another. In this project we used the following types of standard tests:

the uniaxial compression test;

the Brazilian test; and

the three-point bending test.

In addition, $\mathrm{P}$ - and $\mathrm{S}$-wave velocities were measured on specimens prepared for the uniaxial compression tests.

The DSA method (Differential Strain Analysis) was used to quantify the microcracks as it displays changes in the microcrack distribution in a fairly straightforward manner.

Sensitivity criteria influenced our choice of tests, but other factors were even more important. The tests mentioned above provide data which can be used in analytical and numerical analysis of the stability of underground constructions. The parameters determined here are, in fact, the most common in Engineering Rock Mechanics.

\subsection{Starting material}

In the present study we used the grey variety of the well-known granite from the Stripa test site for radioactive waste disposal in Central Sweden. Table I shows the mineral composition of this rock. The average grain size of the granite varies a great deal from one locality to another (Table I). A close look at Fig. $11 \mathrm{~A}-\mathrm{I}$ reveals, however, that the grain size in our specimens is probably smaller than $0.7 \mathrm{~mm}$. The figure also shows that the texture of the rock is rather complex with relatively good grain bonding.

It was not possible to find a collection of samples of a granite with a wide range of microcrack densities, so microcracks had to be produced artificially, and heat treatment was then the obvious solution to the problem. If mineral alterations are to be avoided, specimens must be subjected to this treatment only for a short period of time. Shock heating for $3 \mathrm{~h}$ proved to be enough for a core $42 \mathrm{~mm}$ in diameter to reach a predetermined temperature in the range $20-600^{\circ} \mathrm{C}$. The heattreatment was carried out at 100, 150, 200, 300, 450 and $600^{\circ} \mathrm{C}$. A slight change in colour was noticed for cores heated to 450 and $600^{\circ} \mathrm{C}$. It is possible that this was a result of minor mineral alterations, but it seems even more likely that it was due to the development of a great number of microcracks, as this would result in a change in the absorption of light.

\section{TABLE I}

Mineral composition (vol.\%) and range of average grain size of Stripa granite (grey variety)

\begin{tabular}{ll}
\hline Mineral & Vol.\% \\
\hline Quartz & 35 \\
Plagioclase & 35 \\
Microcline & 24 \\
Muscovite & 2 \\
Chlorite & 3 \\
Accessories & 1 \\
\hline Average grain size (mm) & $0.4-3$ \\
\hline
\end{tabular}




\subsection{Specimen preparation}

Pieces of cores of Stripa granite having a diameter of about $42 \mathrm{~mm}(41.3-41.9 \mathrm{~mm})$ and lengths of about $250 \mathrm{~mm}$ were divided into seven groups, six of which were shock heated to the temperatures mentioned above, and the remaining one was left at room temperature. One group of five samples was treated at each temperature. The samples were put in a hot oven and left there for $3 \mathrm{~h}$ at a constant predetermined temperature. They were then taken out of the oven and simply left on a table to cool down. It should perhaps be pointed out that all samples were about $10 \mathrm{~cm}$ longer than necessary to obtain a microcrack distribution that was as uniform as possible along the axes of the specimens.

All heat-treated samples were prepared for three-point bending. A straight single-edge notch $-10 \mathrm{~mm}$ deep at its centre and $1 \mathrm{~mm}$ wide-was cut across the specimen at half length. The remnants from the three-point bending tests were later used for uniaxial compression tests and Brazilian tests. Specimen preparation for these tests were carried out according to ISRM's Suggested Methods (Brown, 1981). The length of the uniaxial compression specimens varied in the range $80.0-84.1 \mathrm{~mm}$, while the variation in thickness of the Brazilian specimens was confined to the interval $21.0 \pm 0.1 \mathrm{~mm}$.

DSA specimens and petrographic thin sections were prepared from rock cores having undergone the heat-treatment mentioned above. The DSA specimens were cut from these cores to the size and geometry indicated in Fig. 1. The flat surfaces were first ground with $800 \mathrm{SiC}$ powder, and 9 strain gauges (see the sketch in Fig. 1) were then bonded on the three faces with HBM Z70 quick-setting glue. Another two were fixed onto a piece of silica glass, which was used as a reference with well-known elastic properties. The specimens were finally evacuated for about $1 \mathrm{~h}$ before being painted with an HBM varnish and hermetically sealed in a $1 \mathrm{~mm}$ thick coating of LATEX rubber.

Polished thin sections for optical and electron microscopy were prepared from epoxy-impregnated rock samples. The epoxy (Epo-tek 301) was mixed with Fluorescein sodium salt (soluble in the

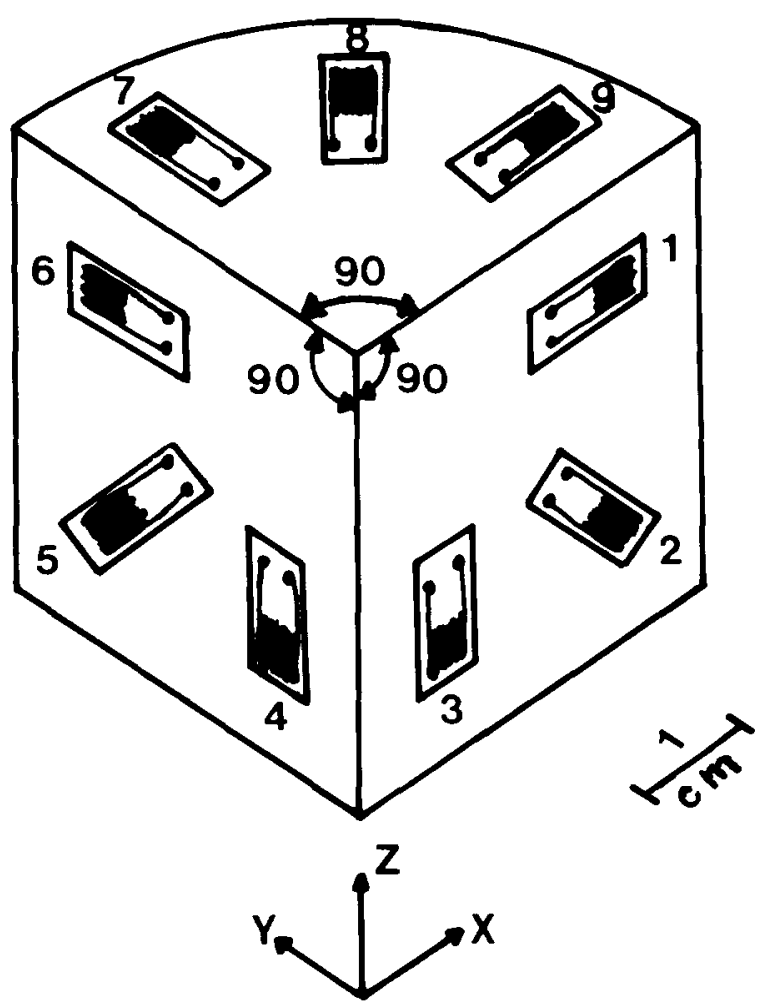

Fig. 1. Sketch of a DSA specimen.

hardener) to allow fluorescence microscopy. A thin carbon layer was vacuum-evaporated onto the sections studied in the scanning electron microscope (SEM).

\subsection{Experimental details}

Before going into details about each specific test, it is advisable to draw attention to a few general experimental conditions. All tests were carried out at room temperature which may fluctuate a couple of degrees from one day to another. The moisture in the specimens-with the exception of the DSA ones-was allowed to equilibrate with that of the laboratory air for a few days prior to the testing.

\subsubsection{Three-point bending tests}

Three-point bending tests were essentially carried out according to the procedures recommended by Sun (1983). The data acquisition and data 
reduction routines have been modified (see Kou and Alm, 1985a, for details). A $32 \mathrm{~K}$-byte ABC 800 microcomputer was used to store and analyse the data, and to calculate values for the rock parameters. The tests were carried out in an INSTRON $100 \mathrm{kN}$ servohydraulic testing machine, which was controlled by the signal from a crack opening displacement gauge mounted across the notch.

\subsubsection{Brazilian tests}

These tests were conducted in accordance with the ISRM's Suggested Methods (Brown, 1981) apart from the fact that our tests were carried out at a constant displacement rate rather than at a constant loading rate. The $100 \mathrm{kN}$ INSTRON press was utilized in these tests too.

\subsubsection{Uniaxial compression tests}

The uniaxial compression tests (henceforth called U.C. tests) were essentially carried out in accordance with recommended procedures (Brown, 1981). The load was applied by a 4.5 MN INSTRON servohydraulic testing machine operated in position control, which means that the specimens were deformed at a constant displacement rate of about $1.4 \cdot 10^{-3} \mathrm{~mm} \mathrm{~s}^{-1}$. The experiments were thus terminated within $\sim 10 \mathrm{~min}$. Axial and radial strains were recorded by two pairs of strain gauges affixed diametrically at half the length of the specimens. The experimental data were recorded by an $\mathrm{X}-\mathrm{Y}$ recorder and also by the $\mathrm{ABC}$ 800 microcomputer.

Prior to testing, all U.C. specimens were subjected to sound velocity measurement, which was carried out at a small axial stress of $2.7 \mathrm{MPa}$ using a Pundit Digital Ultrasonic Tester and a digital oscilloscope.

\subsubsection{DSA experiments}

The DSA method for quantification of microcracks was developed by Simmons and Coworkers in the early seventies, and they have published several papers which describe the experimental technique and evaluation procedures in detail (e.g., Simmons et al., 1974; Siegfried and Simmons, 1978). The idea of the experiment is to measure compressive strain in a rock specimen in six differ- ent directions as a function of applied hydrostatic pressure. This enables the complete strain tensor to be determined for different pressures.

Our experiments were carried out in a $70 \mathrm{~mm}$ bore piston and cylinder apparatus using ESSO UNIVIS J18 hydraulic oil as the confining medium. The loading force on the piston was increased in steps up to a load which produced a pressure of $200 \mathrm{MPa}$, and which was well beyond the pressure required to close all narrow flat cracks. Small spherical cavities may, however, need much higher pressures before they collapse, but they are generally considered insignificant for the properties of the rock unless numerous and interconnected by other open cracks.

Eleven strain gauges, nine on the specimen and two on the silica glass plate were in use in each experiment. The gauges were connected to 12 electrical high-pressure lead-throughs. Six of the gauges on the specimen were measuring strains pairwise in three different directions. The other three recorded the strains in the other necessary directions. One of the remaining gauges on the glass plate was used for reference when reading all the others, including the second gauge on the glass plate (no. 10 in Fig. $8 \mathrm{~A}-\mathrm{C}$ ), which was used for keeping trace of the variation in gain and the zero drift of the measuring system. Our results seemed more reliable after these modifications, since the data acquisition system and the loading sequence, which were automatically controlled by our $\mathrm{ABC}$ 800 microcomputer, permitted only zero adjustment before the start of the experiment. During the loading the pressure was increased in steps of 1 $\mathrm{MPa}$ up to $20 \mathrm{MPa}$, and after that the steps were successively increased to 2,5 and finally $10 \mathrm{MPa}$.

The strain measurements were carried out as follows: the strain gauges were connected one at a time to a Wheatstone bridge circuit together with the reference and two dummy resistors in a way which eliminated any effects of pressure and small temperature changes. The selection of strain gauges was automatically performed by the computer, which also was programmed to record the readings when the signal from every strain gauge differed less than three microstrains from the previous reading. 


\subsection{Results}

All data points in the diagrams presented here are mean values from five tests. As there are different sign conventions regarding stresses and strains, it should be pointed out that compressive stresses and strains are assumed to be positive throughout this paper.

\subsubsection{Bending tests}

The bending strength, $\sigma_{\mathrm{B}}$, has been calculated according to eq. 1 .

$$
\begin{aligned}
\sigma_{\mathrm{B}}= & F_{\max } /\left[\frac{\Phi^{2}}{4} \cdot\left(\pi-\arcsin \left(2 \cdot[h(\Phi-h)]^{1 / 2} / \Phi\right)\right)\right. \\
& \left.+[h(\Phi-h)]^{1 / 2} \cdot(\Phi / 2-h)\right]
\end{aligned}
$$

where $F_{\max }$ is the maximum failure load, $\Phi$ the diameter of the specimen, and $h$ the notch depth. Results for the seven heat-treatment temperatures are shown in Fig. 2. The general tendency of a decreasing bending strength with increasing heat -treatment temperature is interrupted by a weak maximum around $100^{\circ} \mathrm{C}$.

The Young's modulus of the rock can be determined from the load versus load-point displacement curve. Results from these experiments are displayed in Fig. 5 together with similar results from the uniaxial compression tests.

The fracture toughness is now being analysed in

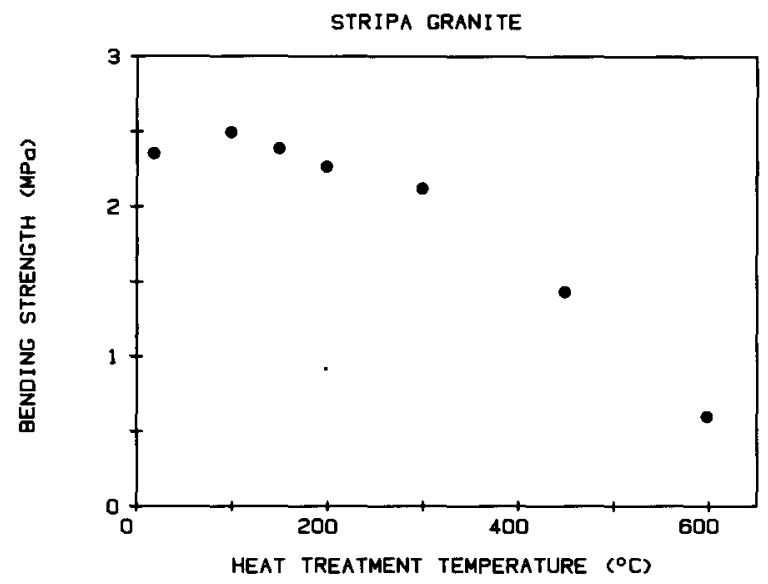

Fig. 2. Bending strength of heat-treated Stripa granite. accordance with procedures suggested by Sun (1983). Preliminary results indicate a tendency similar to that of the bending strength (see Kou and Alm, 1985a). These data require a more thorough analysis before we can say anything more definite about their validity. The concept of linear elastic fracture mechanics could, for instance, be inappropriate for rock material heat-treated at very high temperatures.

\subsubsection{Brazilian tests}

The Brazilian test is a rather insensitive test for studying variations in the tensile strength of rocks due to microstructural changes in the starting material, but it is widely used in Rock Mechanics. Equation 2 gives the formula used for calculating this strength.

$\sigma_{\mathrm{T}}=0.636 \cdot F_{\max } / \Phi t$

$F_{\max }$ and $\Phi$ represent the same variables as before, and $t$ stands for the thickness of the specimen, which in this case was equal to half the diameter. Our results are summarized in Fig. 3. We see quite a perceivable maximum for specimens heat-treated at $100^{\circ} \mathrm{C}$; a decrease in tensile strength with increasing microfracturing should be expected.

\subsubsection{Uniaxial compression tests}

Quite an extensive amount of data can be extracted from U.C. tests, but for the sake of clarity we restrict ourselves to displaying a few typical

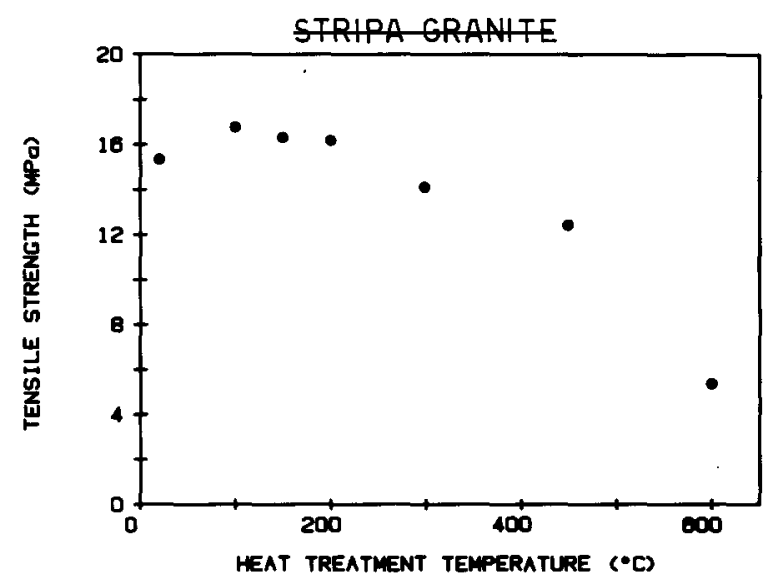

Fig. 3. Tensile strength of heat-treated Stripa granite. 


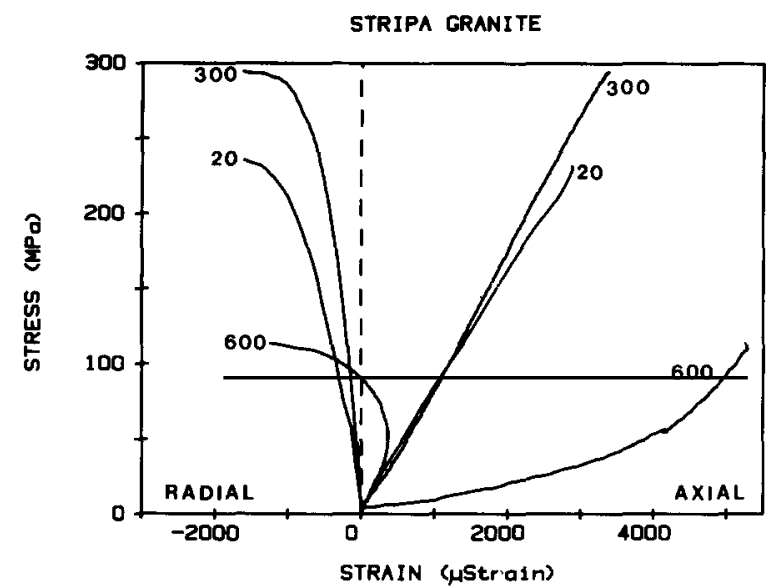

Fig. 4. Typical stress-strain curves for specimens heat-treated at 20,300 and $600^{\circ} \mathrm{C}$.

stress-strain curves and presenting results on the compressive strength and the elastic parameters, the Young's modulus, $E$, and the Poisson's ratio, $\nu$. The values for the moduli were determined at two different stress levels, $10 \mathrm{MPa}$ and a level corresponding to about $25 \%$ of the compressive strength of each specimen. The two sets of values are distinguished from each other by adding the subscript INIT and 25, respectively, to the symbols of these parameters.

Typical stress-strain curves for specimens heattreated at 20 (i.e., non-heated), 300 and $600^{\circ} \mathrm{C}$ are shown in Fig. 4. Generally speaking, the curves look much the same for specimens heat-treated at temperatures in the range $20-300^{\circ} \mathrm{C}$. Beyond that we find a marked decrease in stiffness (see also Fig. 5), and this is particularly noticeable for the specimens heat-treated at $600^{\circ} \mathrm{C}$. The latter also behaved abnormally at low stresses. The radius of the specimens actually decreased with increasing axial stress over the first $50 \mathrm{MPa}$ or so. This behaviour is neither an artifact nor a result of specimen preparation; a U-shaped deformation gauge fitted across the diameter of the specimens in a couple of the experiments recorded similar changes.

The variation of the Young's modulus with heat-treatment temperature is shown in Fig. 5, while corresponding results for the Poisson's ratio are displayed in Fig. 6. Values for the Young's

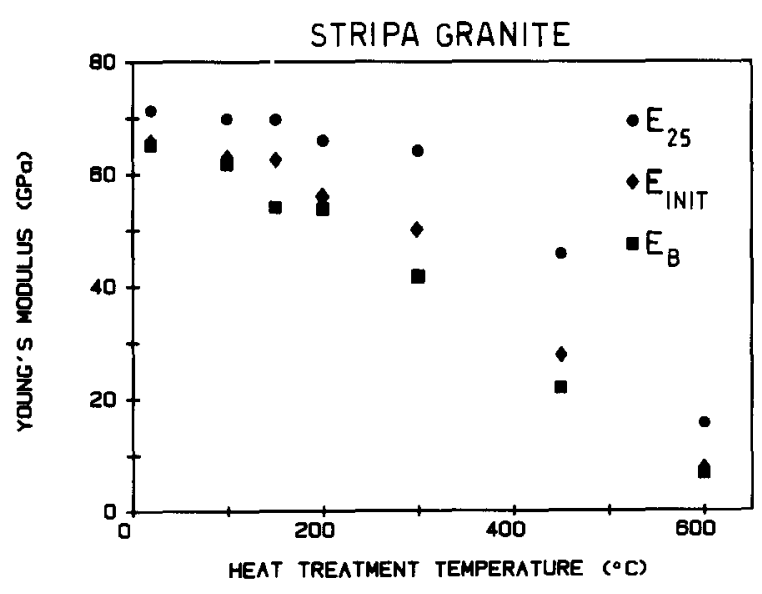

Fig. 5. Young's modulus of heat-treated Stripa granite. $E_{25}$ is determined at a stress level corresponding to $25 \%$ of compressive strength, $E_{\text {INIT }}$ is calculated at $10 \mathrm{MPa}$ axial stress, and $E_{\mathrm{B}}$ is obtained from the bending tests.

modulus obtained from the bending tests (subscript B) are also presented in Fig. 5 to facilitate comparison between the two methods. All three sets of values show a monotonous decrease with increasing heat-treatment temperature, even though the slopes differ from one set to another. The compressive strength shows quite a different dependence on the heat-treatment temperature, revealing a maximum strength for specimens heattreated at $450^{\circ} \mathrm{C}$ (see Fig. 7).

\subsubsection{DSA experiments}

Figure $8 \mathrm{~A}-\mathrm{C}$ shows the differential strain readings versus applied pressure for three specimens containing different amounts of microcracks. The difference between Fig. 8C and the other two, is quite striking. If we differentiate these curves once with respect to pressure, we can calculate the zero-pressure strain due to the presence of cracks closing completely at pressures less than that at which the differentiation is carried out. Here we call this the crack closure strain. The second derivative of the curves can be used to determine the zero-pressure strain due to cracks closing in a unit pressure interval. This is called the crack spectrum. The reader is referred to Siegfried and Simmons (1978) for a more detailed theoretical analysis of the experiment. 


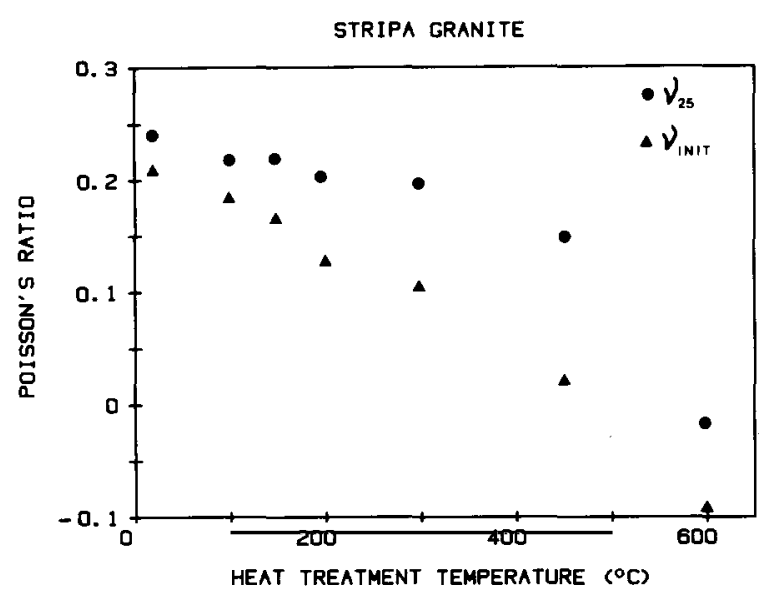

Fig. 6. Poisson's ratio of heat-treated Stripa granite. The subscripts have the same meaning as in Fig. 4.

Plots of the principal values of the crack spectra and the directions of the corresponding principal axes are displayed in Fig. 9. The most conspicuous feature in this figure is the pronounced dominance of one principal direction over the other two. We see that the peak becomes higher-and the area under it accordingly larger - with increasing heattreatment temperature (note that the scale on the $\mathrm{Y}$-axis for the 450 and the $600^{\circ} \mathrm{C}$ sample is not the same as for the other samples). We also find a weak tendency for the peak to shift towards lower pressures with increasing heat-treatment tempera-

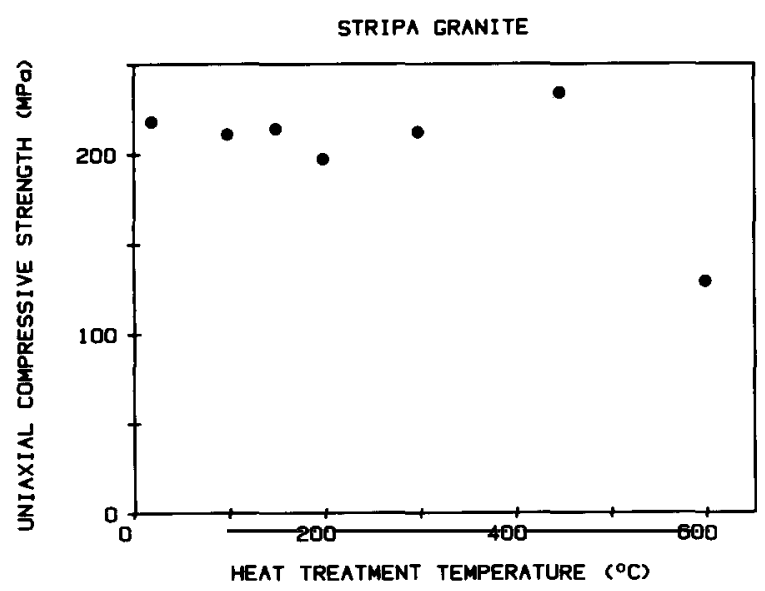

Fig. 7. Uniaxial compressive strength of heat-treated Stripa granite (after Kou and Alm, 1985a).
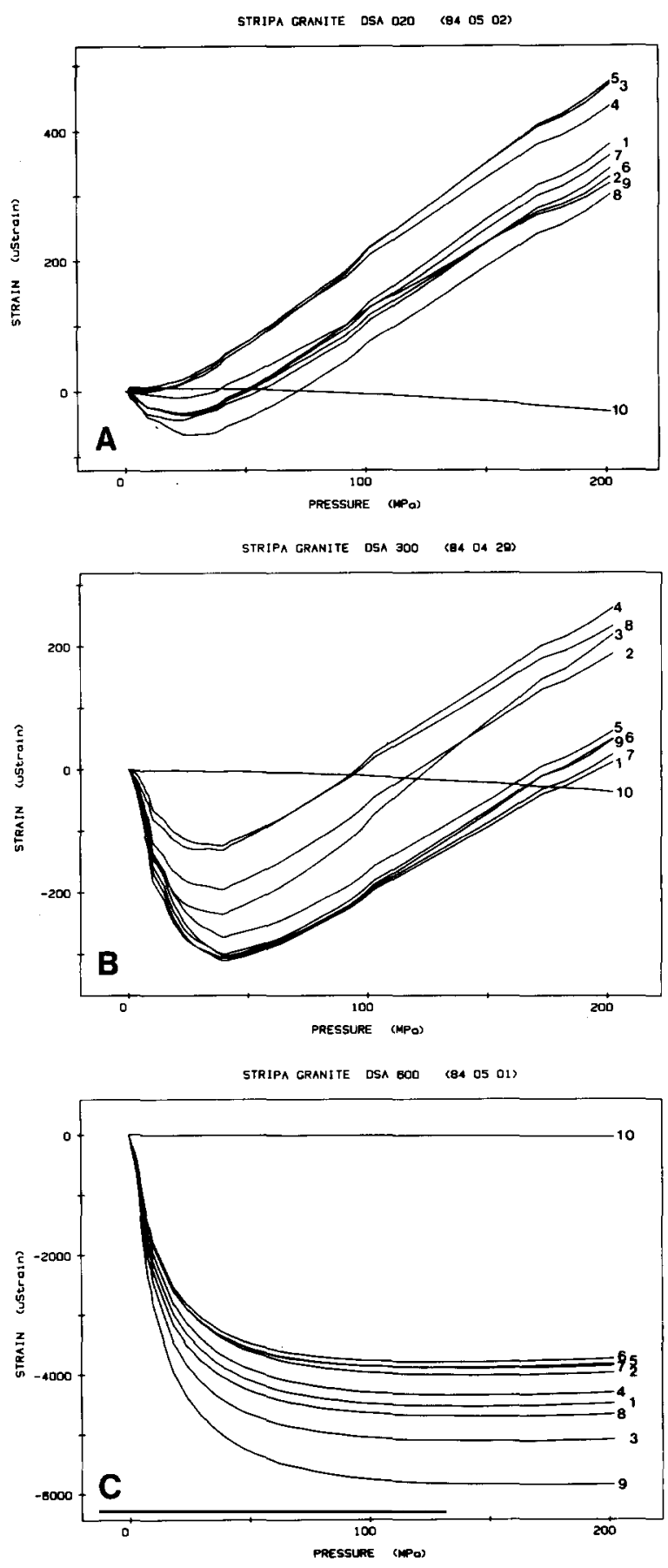

Fig. 8. Differential strain (sample strain minus strain in the fused silica reference sample) versus hydrostatic pressure for specimens heat-treated at $20^{\circ} \mathrm{C} \mathrm{(A),} 300^{\circ} \mathrm{C}$ (B) and $600^{\circ} \mathrm{C}$ (C). Curves 1-9 are obtained from strain gauges on the specimens. Curve 10 refers to a second strain gauge on the glass plate. 

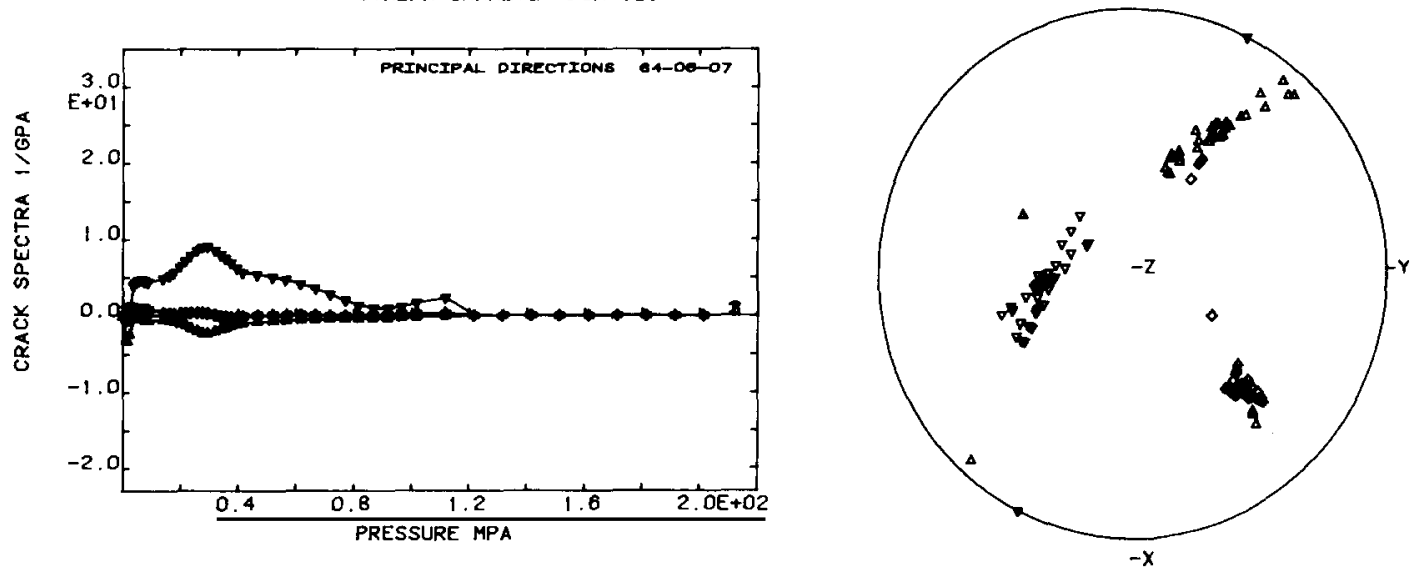

STRIPA GRANITE DSA 100

STRIPA GRANITE DSA 180

PRINCIPAL CRACK SPECTRA DIRECTION
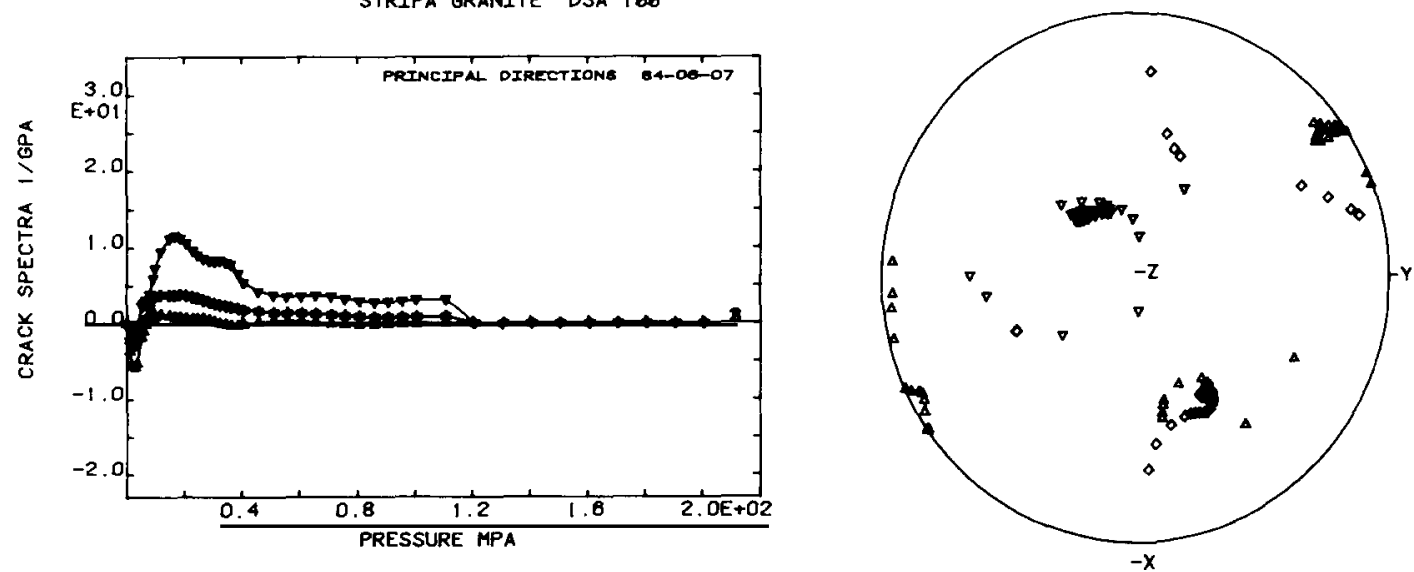

STRIPA GRANITE DSA 150

STRIPA GRANITE DSA 150

PRINCIPAL CRACK SPECTRA DIRECTION
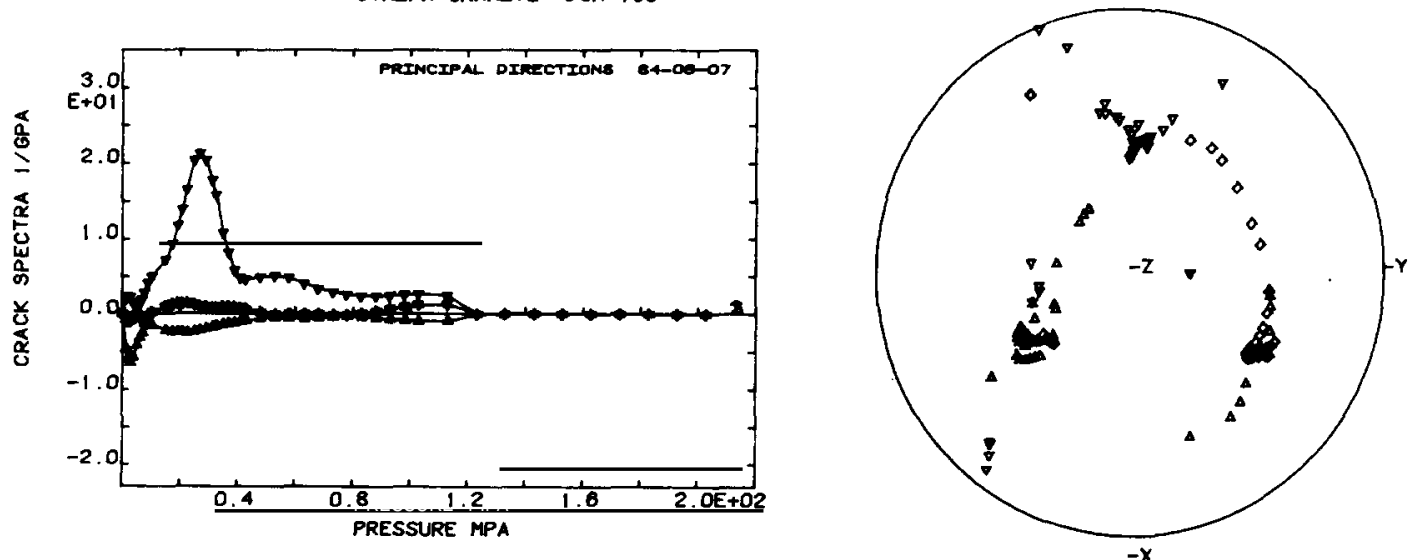

Fig. 9. Crack spectra, i.e., the zero-pressure strain due to cracks closing in a unit pressure interval, in the principal directions and stereographic plots of the directions of these principal axes at different confining pressures. The heat-treatment temperatures are given in the text above each diagram (e.g., DSA 150 means heat-treated at $\left.150^{\circ} \mathrm{C}\right) ; \nabla$-maximum principal direction, $*$ (left diagram) and $\diamond$ (stereogr. plot)-medium principal direction, $\triangle$-least principal direction. 
STRIPA GRANITE DSA 200

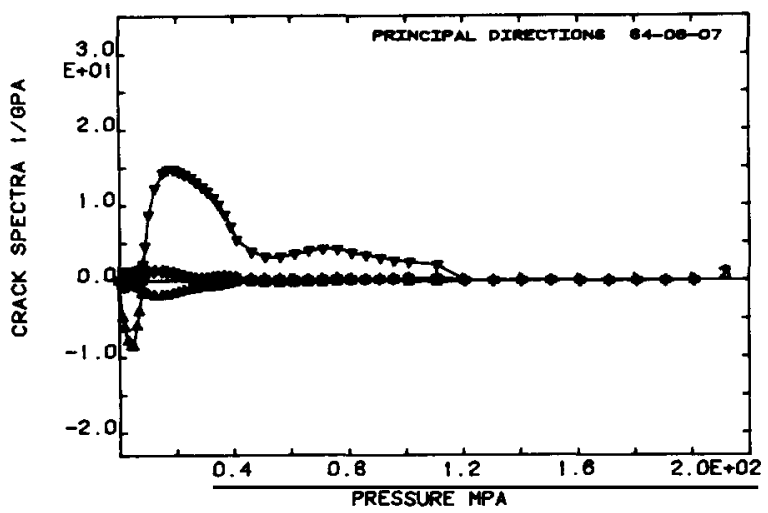

STRIPA GRANITE DSA 300

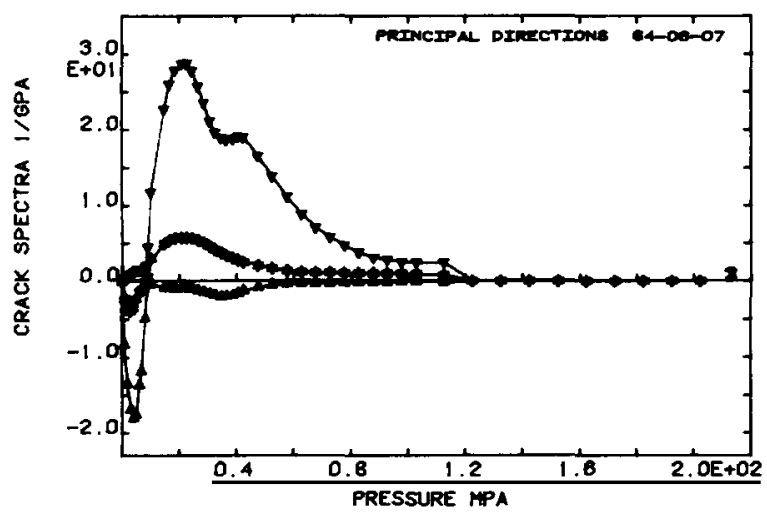

STRIPA GRANITE DSA 450

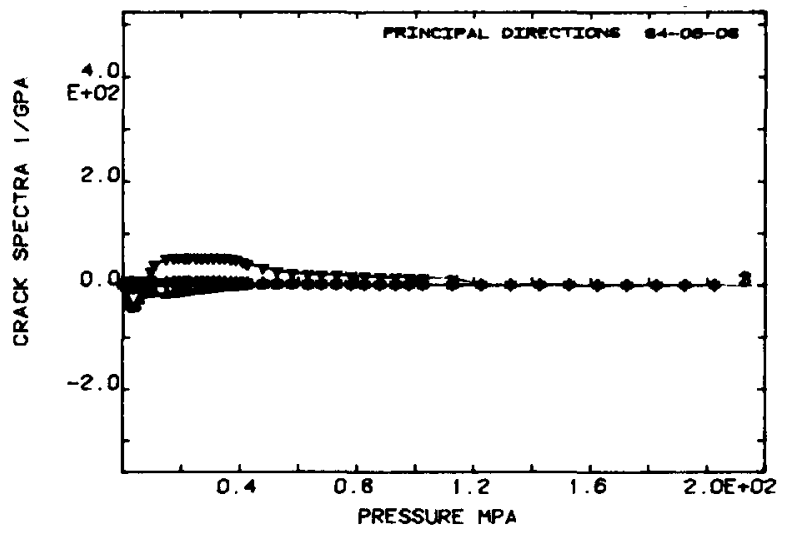

STRIPA GRANITE DSA 200 PRINCIPAL CRACK SPECTRA DIRECTION

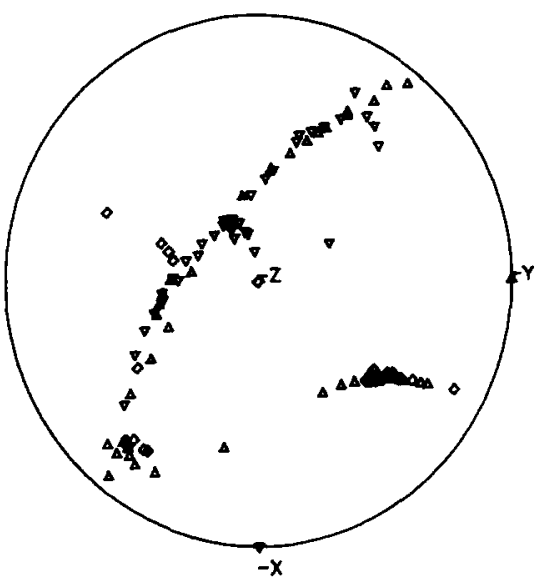

STRIPA GRANITE DSA 300 PRINCIPAL CRACK SPECTRA DIRECTION

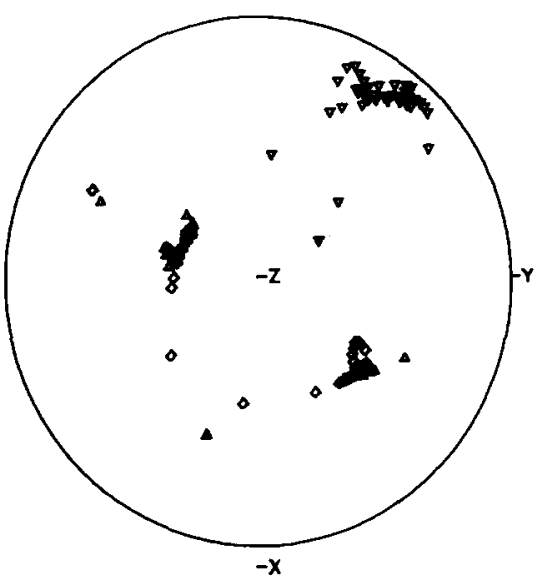

STRIPA GRANITE DSA 450 PRINCIPAL CRACK SPECTRA DIRECTION

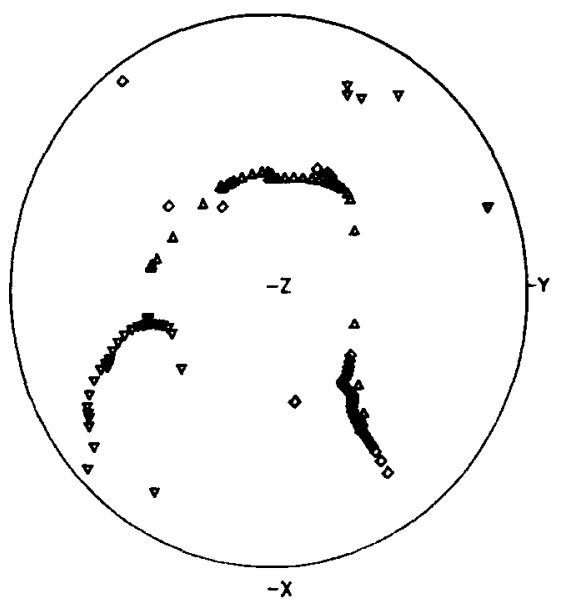




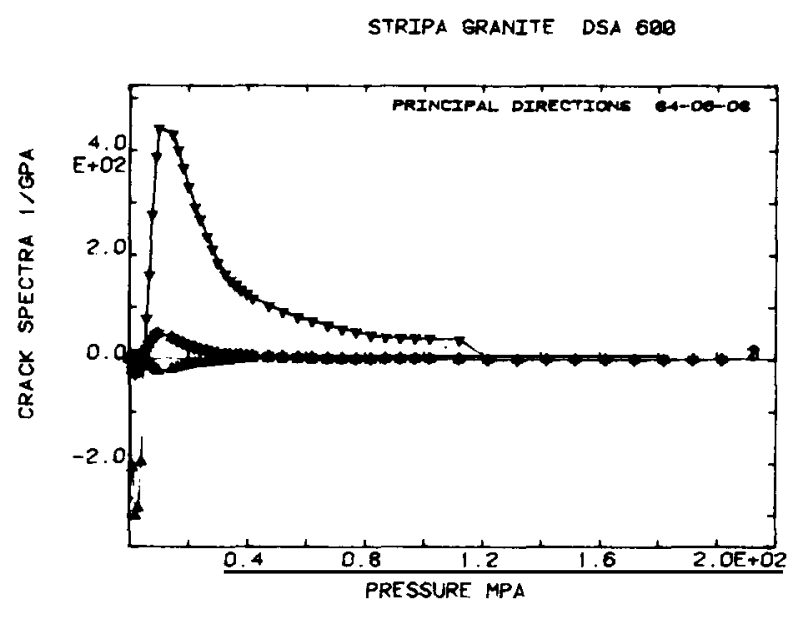

ture. The crack spectra show that most cracks close at pressures below $50 \mathrm{MPa}$. The principal axes are fairly well defined, though a larger scattering is found in the 200 and the $450^{\circ} \mathrm{C}$ sample, and surprisingly enough we see that the $600^{\circ} \mathrm{C}$ sample has the best defined principal directions of all. The negative spikes preceding the main peaks are artifacts of the curve-fitting procedures and can be completely disregarded.

The crack-closure strain obtained from the first derivative of the differential strain curves is a

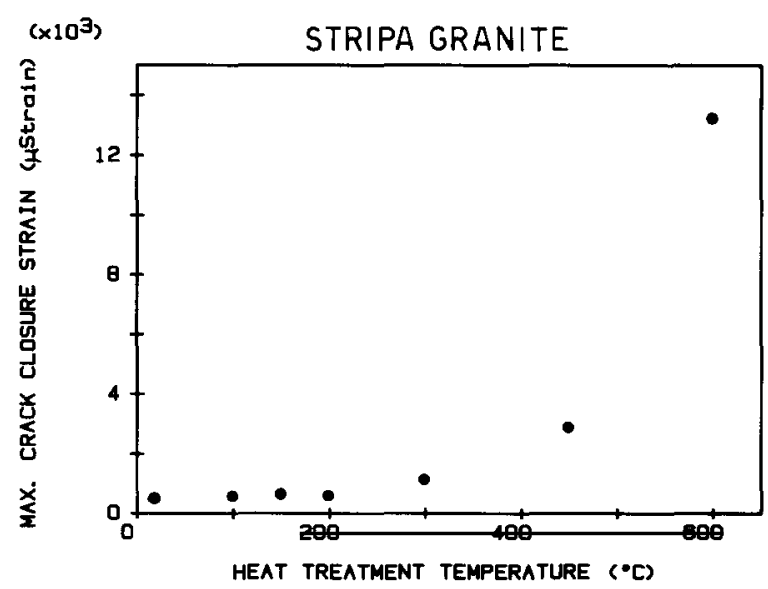

Fig. 10. Zero-pressure strain due to cracks closing completely at $200 \mathrm{MPa}$ confining pressure, maximum crack closure strain, versus heat-treatment temperature; maximum principal direction only.

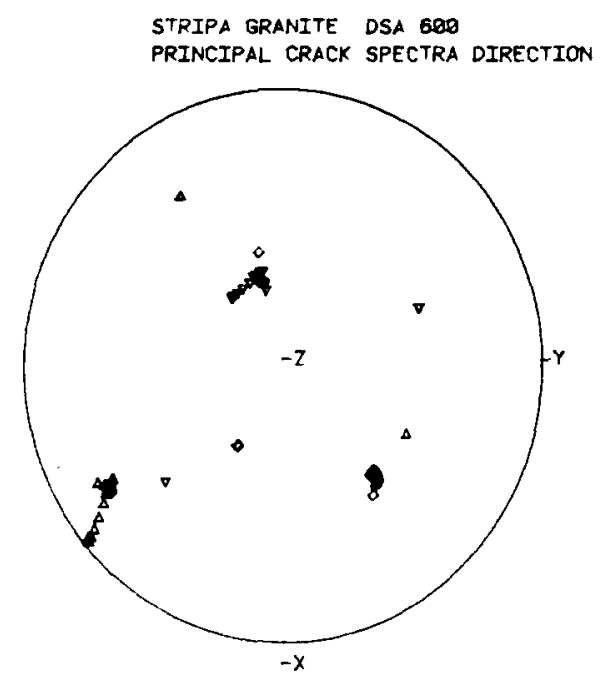

measure of the volume occupied by microcracks, i.e., the density of microcracks, and the maximum values are determined at $200 \mathrm{MPa}$ pressure. We see from Fig. 10 that the amount of microcracks increases drastically in the samples heat-treated above $300^{\circ} \mathrm{C}$.

\subsubsection{Microscopy}

The microcracks were directly observed in an optical and a scanning electron microscope. Figure 11 A-I shows a collection of optical micrographs from a few areas which are representative for the rock samples with the assigned heat-treatment temperatures. Thin sections representing all heattreatment temperatures have been examined, but very little change was noticed in the range up to $200^{\circ} \mathrm{C}$. This group will therefore be represented by the $20^{\circ} \mathrm{C}$ sample. Figure $11 \mathrm{~A}-\mathrm{D}$ is taken at a relatively low magnification to give a general view of the texture of the rock and the abundance of cracks. There are few observable cracks in all these pictures, probably because it is difficult to distinguish a grain boundary containing a narrow crack from a crack-free one. The $600^{\circ} \mathrm{C}$ sample is, however, an exception, and the same seems to be true for the $450^{\circ} \mathrm{C}$ case too. There were doubtlessly cracks in the other samples-even the nonheated one (Fig. 11E), although they were few in number, and seemed to be even more restrained to grain boundaries (GB cracks) than those found in 

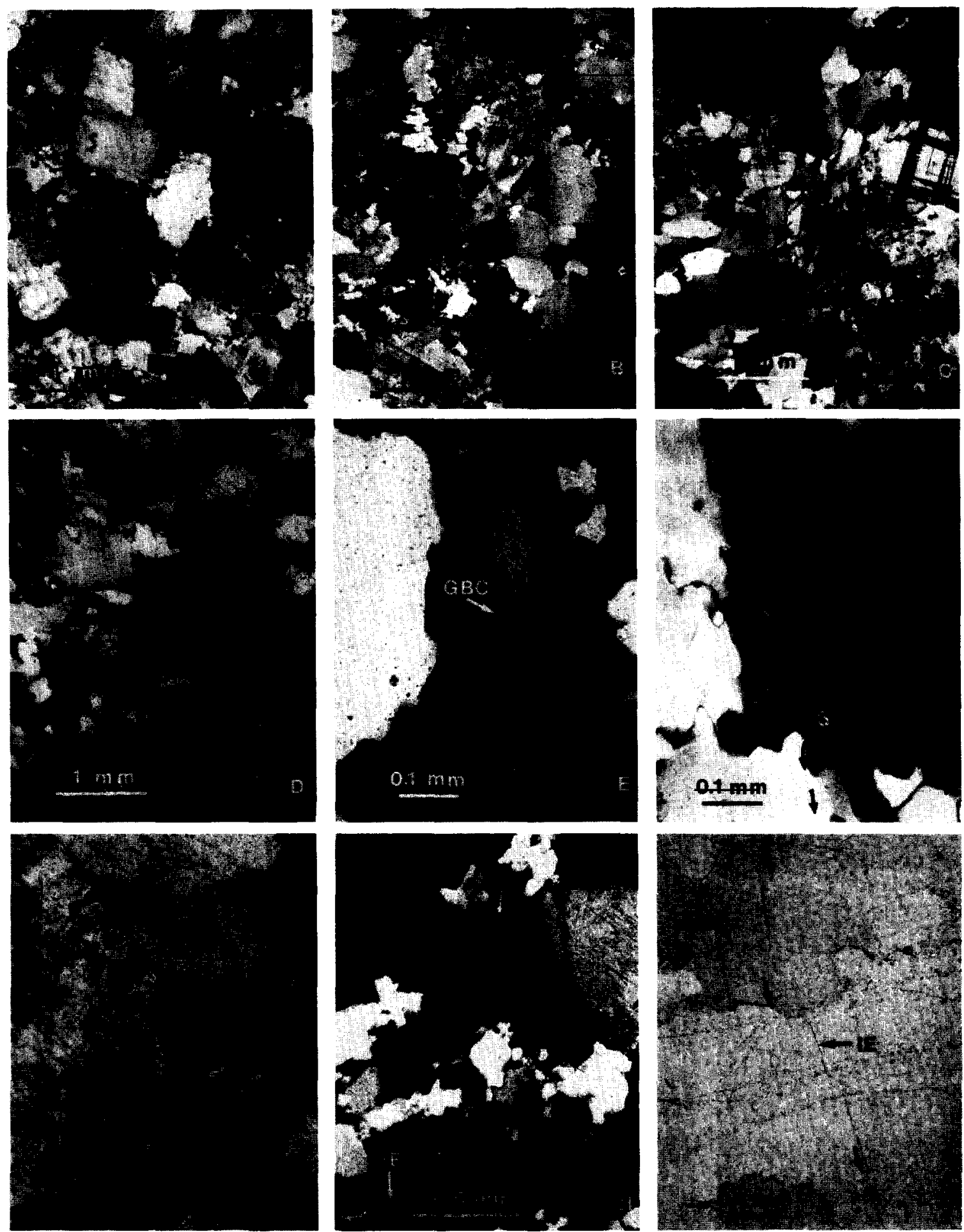

Fig. 11. Optical micrographs of thin sections of heat-treated Stripa granite, crossed nicols except I (polarized light only). A-20 ${ }^{\circ} \mathrm{C}$, B- $-300^{\circ} \mathrm{C}, \mathrm{C}-450^{\circ} \mathrm{C}, \mathrm{D}-600^{\circ} \mathrm{C}, \mathrm{E}-20^{\circ} \mathrm{C}, \mathrm{F}-300^{\circ} \mathrm{C}, \mathrm{G}-450^{\circ} \mathrm{C}, \mathrm{H}-600^{\circ} \mathrm{C}$, and $\mathrm{I}-450^{\circ} \mathrm{C}$; IE-intergranular cracks IA-intragranular cracks, GBC-grain boundary cracks, S-subgrain. 

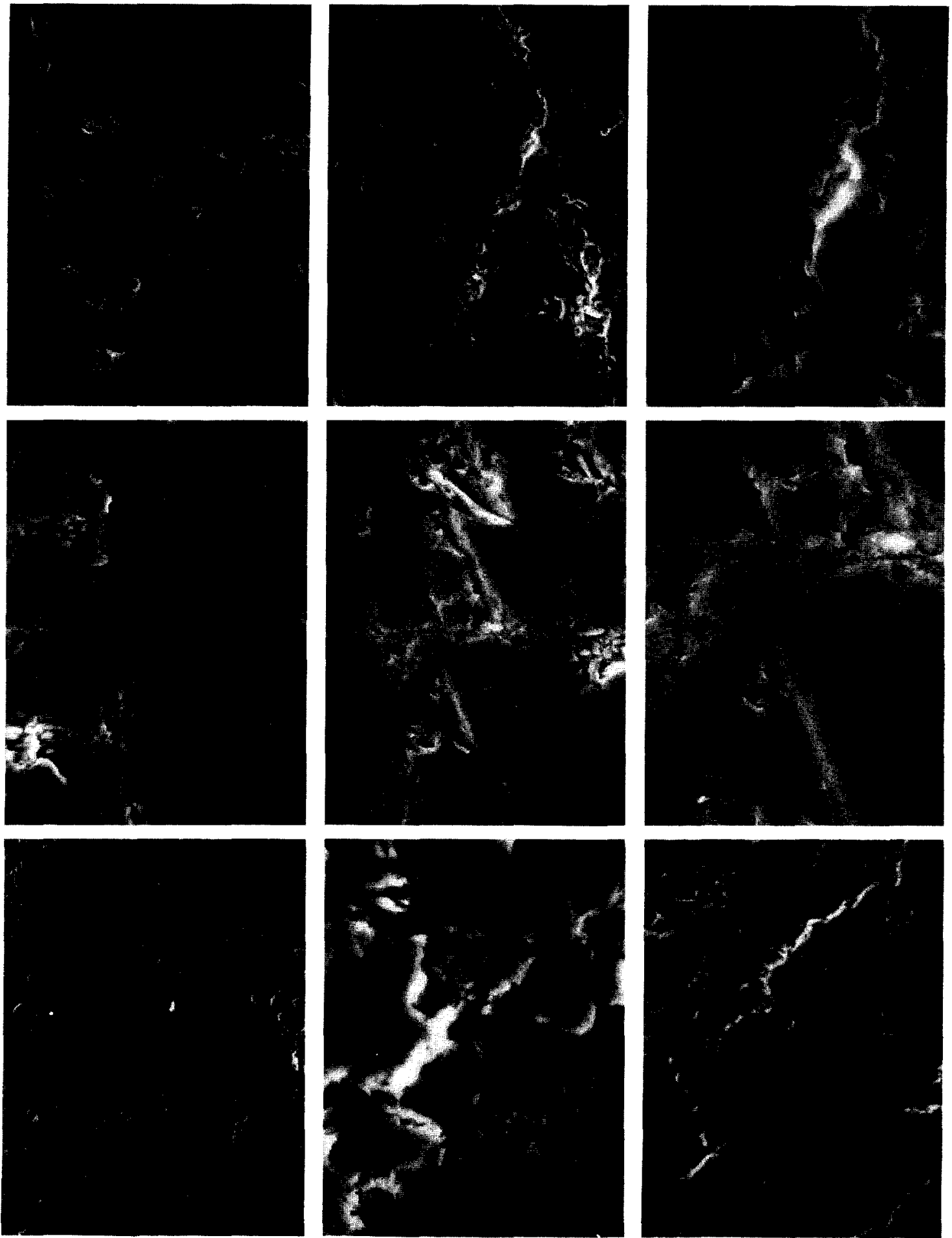

Fig. 12. SEM micrographs, $20 \mathrm{kV}$, SEI. A-C $-300^{\circ} \mathrm{C}, \mathrm{D}-\mathrm{F}-450^{\circ} \mathrm{C}, \mathrm{G}-\mathrm{I}-600^{\circ} \mathrm{C}$; IA-intragranular cracks, T-transgranular cracks, GBC-grain boundary cracks, GBU-uncracked grain boundary, C-crushed region, P-pieces in grain boundaries, E-epoxy layer in grain boundary, Q-quartz grain, MI-microcline grain. Figure $\mathrm{C}$ is an enlargement of the area marked with a square in Fig. $\mathrm{B}$, and $\mathrm{H}$ an enlargement of the square in $\mathbf{G}$. 

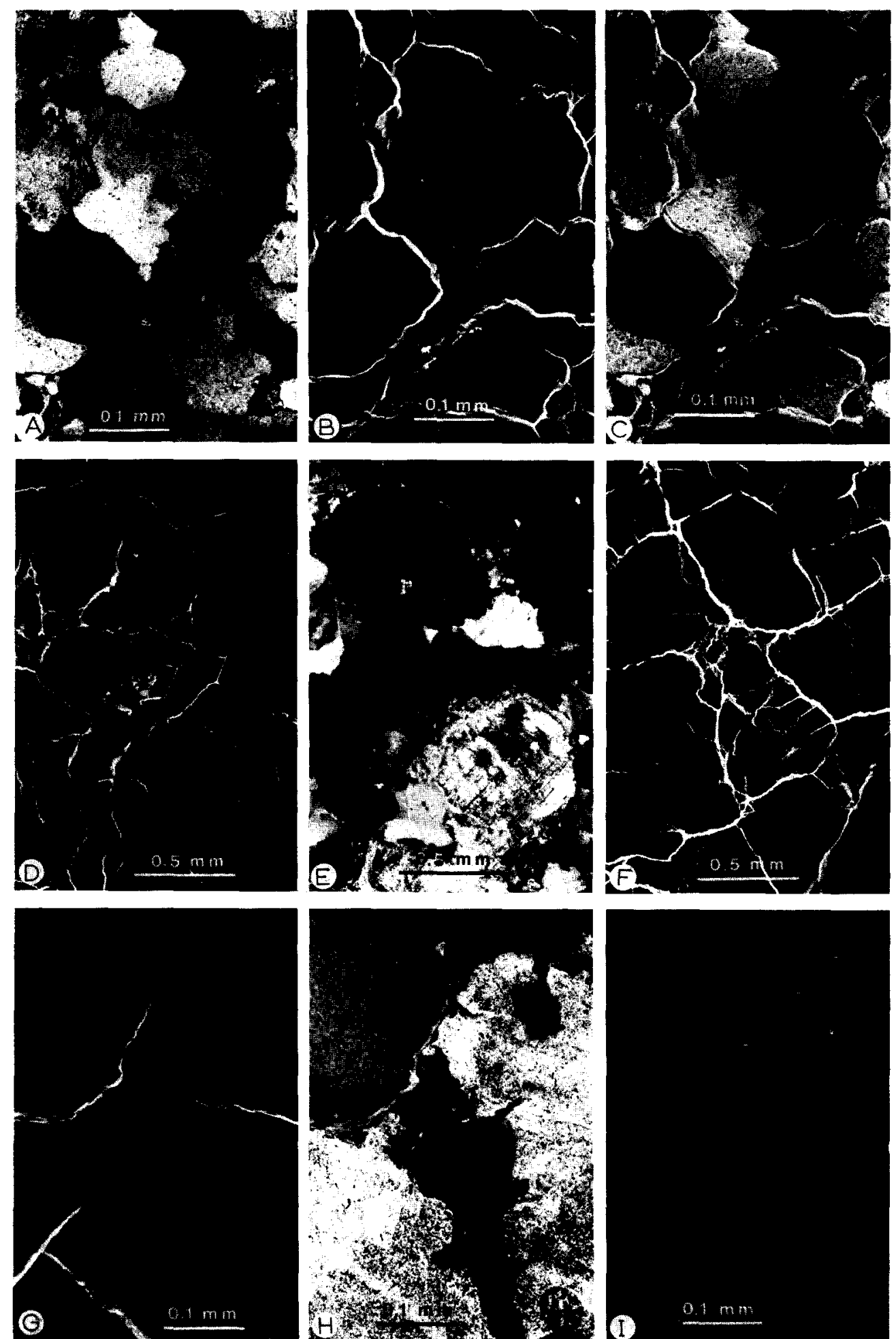

Fig. 13. Optical micrographs-fluorescence microscopy. A- $-600^{\circ} \mathrm{C}$ crossed nicols, B- $600^{\circ} \mathrm{C}$ fluorescence light, $\mathrm{C}-600^{\circ} \mathrm{C}$ both transmitted light, crossed nicols, and fluorescence light (the same area as in $\mathrm{A}$ and $\mathrm{B}$ ), $\mathrm{D}-600^{\circ} \mathrm{C}$ fluorescence light (another area), E- $600^{\circ} \mathrm{C}$ both transmitted light, crossed nicols, and fluorescence light (the same area as in D), F-600 ${ }^{\circ} \mathrm{C}$ fluorescence light (still another area-note the great number of intra- and transgranular cracks in the central grain), $\mathrm{G}-450^{\circ} \mathrm{C}$ fluorescence light, $\mathrm{H}$-both transmitted light, crossed nicols, and fluorescence light (the same area as in $\mathrm{G}$, grain boundary-and transgranular $\mathrm{cracks}$ ), I-300 ${ }^{\circ} \mathrm{C}$ fluorescence light (grain boundary cracks). 
samples heat-treated at the highest temperatures (Fig. $11 \mathrm{~F}-\mathrm{H}$ ). Intergranular cracks crossing several grains are quite frequent in the high temperature samples, especially in the $600^{\circ} \mathrm{C}$ one.

Another technique, scanning electron microscopy, can help to overcome the difficulty in discriminating crack-free grain boundaries from those containing cracks. Figure $12 \mathrm{~A}-\mathrm{I}$ shows micrographs from a SEM study of sections from samples heat-treated at 300,450 and $600^{\circ} \mathrm{C}$. Comparing the three rows in Fig. 12 we find that grain boundaries become more visible the higher the heat-treatment temperature is, and this is probably a result of increasing cracking along these boundaries. Figure 12A displays part of a long crack running along several grain boundaries in a $300^{\circ} \mathrm{C}$ sample. Small pieces surrounded by cracks are often seen along grain boundaries in the $450^{\circ} \mathrm{C}$ and the $600^{\circ} \mathrm{C}$ samples (Fig. $12 \mathrm{D}-\mathrm{I}$ ), and occasionally we find areas with extensive cracking, almost crushing, in the $600^{\circ} \mathrm{C}$ sample (Fig. 12 $\mathrm{H}-\mathrm{I}$ ). A careful look at Fig. $12 \mathrm{H}-\mathrm{I}$ also reveals the existence of some intragranular and transgranular cracks.

Grain boundary cracking is by far the most important crack mechanism in thermally induced microcracking. Virtually all grain boundaries in the $600^{\circ} \mathrm{C}$ sample contain cracks (Fig. $12 \mathrm{G}-\mathrm{I}$ ). Much less cracking is found along the grain boundaries in the $300^{\circ} \mathrm{C}$ one (Fig. $12 \mathrm{~A}-\mathrm{C}$ ). The prominent crack in Fig. $12 \mathrm{~B}-\mathrm{C}$ continues only along the grain boundary towards the lower righthand corner, leaving the boundary running towards the left-hand corner uncracked.

The time-consuming and rather inexact chemical method of mineral identification is one of the major drawbacks of scanning electron microscopy; although it is necessary to identify the minerals to be able to distinguish GB cracks from transgranular ones, and to see if GB cracks prefer boundaries between certain types of mineral grains. But if the conducting layer is thin enough it is possible to discriminate grains of different minerals even with secondary electrons. In addition, we find that plucking can cause severe electrical charging problems as the resulting pits are difficult to cover with conducting material without making the layer too thick. We have therefore incorporated a third di- rect method, fluorescence microscopy, which makes use of an optical microscope to detect light from a fluoresing material injected into the open cracks, like the one shown in Fig. $12 \mathrm{I}$.

A Leitz II BK polarization microscope was modified to allow orthoscopic microscopy in transmitted light and fluorescence microscopy in the reflected light mode. The micrograph in Fig. 13 A shows the microstructure of a small area in the thin section from a $600^{\circ} \mathrm{C}$ sample. Figure $13 \mathrm{~B}$ displays a picture of the fluorescence light from epoxy-filled cracks in this area, while Fig. $13 \mathrm{C}$ demonstrates the results of a simultaneous use of these two techniques. Microcracks in a couple of other areas in the $600^{\circ} \mathrm{C}$ section are displayed in Fig. $13 \mathrm{D}-\mathrm{F}$. The picture in Fig. $13 \mathrm{~F}$ indicates that intragranular cracks are fairly common in samples heat-treated at $600^{\circ} \mathrm{C}$. Open cracks large enough to allow penetration of the impregnating epoxy were less abundant in the $450^{\circ} \mathrm{C}$ and the $300^{\circ} \mathrm{C}$ samples, and they were almost undetectable in the other samples. Figure $13 \mathrm{G}-\mathrm{H}$ confirms, however, that the $450^{\circ} \mathrm{C}$ sample contains both grain boundary and transgranular cracks wide enough to let the epoxy through. Finally, Fig. 13 I shows a picture of the fluorescence light from a few narrow grain boundary cracks in the $300^{\circ} \mathrm{C}$ sample.

The major disadvantage of the fluorescence technique is that we can only observe open voids and cracks which are connected to the external surface, and which are wide enough to allow the epoxy to penetrate. The minute cracks and the sealed ones will not be detected.

\section{Discussion}

When a multimineralic rock is exposed to high temperatures at atmospheric or low confining pressures microcracks will form. The main factors governing the production of microcracks in heated rocks are, firstly, the differences of thermal expansion coefficients both of the different minerals in the rock and in the minerals themselves (i.e., crystal thermal expansion anisotropy), secondly, the maximum temperature to which the rock is exposed, thirdly, the rate of increase in temperature and 
finally the thermal conductivity of the rock. Shock heating is far more efficient than slow uniform heating when the aim is to produce microcracks. Since the purpose of this investigation was to study the mechanical properties of rock samples holding various amounts of microcracks, we chose to raise the temperature of the samples as quickly as possible.

The estimation of microcrack density is a crucial point when studying the effect of microcracks on rock properties. This could be done through direct observations-for instance by optical and electron microscopy-but this is very expensive and time-consuming, unless it is highly automatized (Montoto et al., 1980; Montoto, 1982). All the same, the results obtained from optical microscopy show these methods to be essential when it comes to establishing the type of cracks generated at different temperatures, even though they are only really suitable for qualitative estimates of crack density. Furthermore, it should perhaps be pointed out that we have not bothered to differentiate between the cracks that were originally present in the rock samples and those that were thermally generated. It is obvious that most of the cracks belong to the latter category.

The DSA results are more readily useful for quantitative analysis. We know, for instance, that the maximum crack closure strain is a measure of the volume of open cracks. Values for this parameter are calculated for the three principal directions. The results in one direction are more than one order of magnitude larger than in the other two.
Accordingly we only pay attention to the dominating one.

Sound velocity is another parameter widely used for estimating variations in crack density (e.g., Johnson et al., 1978; Homand-Étienne and Houpert, 1982). We simply presume that changes in both $\mathrm{p}$ - and s-wave velocities are proportional to the increase in microcrack density.

A crack density parameter can also be obtained from theoretical considerations involving the elastic moduli. If we assume, firstly, that our starting material, the unheated Stripa granite, is isotropic, and secondly, that the distribution of crack locations and crack orientations are sufficiently random and, furthermore, that no interaction takes place between these cracks; then we can calculate the crack density parameter for a continuous, linear elastic cracked body. Budiansky and O'Connell (1976) derived expressions for this parameter assuming all the cracks to have the same shape and one dimension much smaller than the other two. In their paper we find equations for rectangular, circular, and elliptic cracks. The first type is very unlikely, and we will therefore only deal with the other two. The crack density parameter, $\eta$, as defined by Budiansky and O'Connell (1976), is the volume fraction of spheres or ellipsoids circumscribing cracks having circular or elliptic shapes, respectively. Equation 3 gives $\eta$ for circular cracks (subscript C) and eq. 4 for long narrow elliptic cracks (subscript E)

$\eta_{\mathrm{C}}=\frac{45}{16} \frac{\left(\nu_{\mathrm{m}}-\nu\right)(2-\nu)}{\left(1-\nu^{2}\right)\left[10 \nu_{\mathrm{m}}-\nu\left(1+3 \nu_{\mathrm{m}}\right)\right]}$

TABLE II

Calculated values for the crack density parameter and measured sound velocities for heat-treated Stripa granite; $\eta_{25}$ and $\eta_{1 \text { INIT }}$ are obtained from $\nu_{25}$ and $\nu_{\text {INIT }}$ respectively

\begin{tabular}{lllll}
\hline $\begin{array}{l}\text { Heat-treatment } \\
\text { temperature }{ }^{\circ} \mathrm{C}\end{array}$ & $\eta_{25}$ & $\eta_{\text {INIT }}$ & $\begin{array}{l}\mathrm{v}_{\mathrm{p}}{ }^{1} \\
\mathrm{~m} \mathrm{~s}^{-1}\end{array}$ & $\begin{array}{l}\mathrm{v}_{\mathrm{s}}{ }^{1} \\
\mathrm{~m} \mathrm{~s}^{-1}\end{array}$ \\
\hline 20 & -0.10 & 0.01 & 5420 & 3340 \\
100 & -0.02 & 0.08 & 5490 & 3350 \\
150 & -0.03 & 0.14 & 5290 & 3320 \\
200 & 0.03 & 0.24 & 5150 & 3240 \\
300 & 0.04 & 0.30 & 4860 & 3110 \\
450 & 0.18 & 0.52 & 3720 & 2470 \\
600 & 0.61 & 0.80 & 2040 & 1470 \\
\hline
\end{tabular}

\footnotetext{
1 Kou and Alm (1985b).
} 
$\eta_{\mathrm{E}}=\frac{45}{8} \frac{\left(\nu_{\mathrm{m}}-\nu\right)}{(1+\nu)\left[10 \nu_{\mathrm{m}}-\nu\left(1+8 \nu_{\mathrm{m}}\right)\right]}$

where $\nu_{\mathrm{m}}$ is the Poisson's ratio of the uncracked material and $\nu$ the effective Poisson's ratio of the cracked body. The parameter $\nu$ is obtained from sound velocity or uniaxial compression tests of cracked rock. $\nu_{\mathrm{m}}$ should be determined ideally from similar tests on completely uncracked specimens, but as such specimens do not exist we are forced to calculate it. Simmons and Wang (1971) calculated properties of mineral aggregates from single crystal elastic constants using Voigt and Reuss averages. But, as there are no such data available for quasistatic elastic parameters, we simply assume the quasistatic and the dynamic values for the Poisson's ratio to be equal, and calculate the crack-free properties of the Stripa granite from Simmons and Wang's (1971) mineral data and the mineral composition given in Table I. All the subordinate minerals are supposed to have the properties of muscovite. Under these conditions eqs. 3 and 4 give practically the same results. Table II gives mean values of Voigt and Reuss estimates of $\eta$ for the two sets of data for the Poisson's ratio presented in Fig. $6\left(\eta=\left(\eta_{C}+\right.\right.$ $\left.\eta_{\mathrm{F}}\right) / 2$ ). The negative values in the table are due to the fact that the Voigt estimate of the Poisson's ratio of the uncracked material is less than the measured effective Poisson's ratio of the actual rock. Negative crack densities are of course impossible, and these values highlight the discrepancy between the idealized assumptions on which the calculations are based and the actual conditions. Precise values cannot be expected, and our aim is then to get at a functional relationship rather than to present exact figures.

Measured p- and s-wave velocities obtained from Kou and Alm (1985b) are also given in Table II.

Linear regression analyses have been carried out to investigate the relationships between the mechanical data represented by parameter values in Figs. 2-7 and crack density estimates (Fig. 10 and Table II). Table III lists the parameters involved in these analyses, and Table IV presents the results. Note that the two series of crack density parameters and the Poisson's ratios are mutually dependent in a pairwise manner.

The correlations are good in most cases and extremely good in some of them, even if we disregard the dependent pairs. The sound velocities, for instance, correlate well with most parameters and extremely well with the moduli determined from the uniaxial compression tests and the bending and tensile strengths. The latter two also correlate quite satisfactorily with the crack density parameters $\eta_{25}$ and $\eta_{\text {INIT }}$ and the maximum crack closure strain, $\zeta_{\max }$, and so does $\mathrm{E}_{25}$. We also see that $\mathrm{E}_{25}$ and $\nu_{25}$ correlate better with $\zeta_{\max }$ than $\mathrm{E}_{\text {INIT }}$ and $\nu_{\text {INIT }}$ do. The extraordinary non-linear behaviour of the $600^{\circ} \mathrm{C}$ sample and the low signal-to-noise ratio at low stresses are both factors which contribute to the observed differences between $E_{25}$ and $\nu_{25}$ on one hand and $\mathrm{E}_{\text {INIT }}$ and $\nu_{\text {INIT }}$ on the other hand.

TABLE III

List of parameters involved in linear regression analysis $(Y=a+b X)$

\begin{tabular}{ll}
\hline$Y$ & $X$ \\
\hline$E_{\mathrm{B}}$ Young's modulus from bending & $v_{\mathrm{P}}$ p-wave velocity \\
$\sigma_{\mathrm{B}}$ Bending strength & $v_{\mathrm{S}}$ s-wave velocity \\
$\sigma_{\mathrm{T}}$ Tensile strength & $\eta_{25}$ Crack density parameter $\left(\nu_{25}\right)$ \\
$\sigma_{\mathrm{C}}$ Uniaxial compressive strength & $\eta_{\text {INIT }}$ Crack density parameter $\left(\nu_{\text {INIT }}\right)$ \\
$E_{25}$ Young's modulus at $0.25 \sigma_{\mathrm{C}}$ & $\zeta_{\text {max }}$ Max. crack closure strain \\
$E_{\text {INIT Young's modulus at } 10 \mathrm{MPa}}$ \\
$\nu_{25}$ Poisson's ratio at $0.25 \sigma_{\mathrm{C}}$ \\
$\nu_{\text {INIT Poisson's ratio at } 10 \mathrm{MPa}}$ \\
\hline
\end{tabular}


The uniaxial compressive strength correlates badly with all parameters representing the crack density, but this does in fact follow quite logically from the results displayed in Fig. 7. A maximum compressive strength for specimens heat-treated at a temperature as high as $450^{\circ} \mathrm{C}$ was indeed surprising, especially when the values of all other parameters declined steeply at this heat-treatment temperature. The question is then: what causes this abnormal behaviour? Neither optical nor electron microscopy revealed any evidence of an anomalous crack distribution or any changes in the texture of the rock. Consequently, we can only speculate about the possible reasons for this striking result. It could be that major cracks are arrested or deviated into new directions when they run into areas with a certain number of microcracks. Alternatively, we may have a more uniform stress field in these specimens as any preexisting high local stresses might be evened out by thermal cracking. A larger applied stress might then be needed to break the rock. But if the crack density becomes too high, the overall cohesion in the specimen will decrease to a level where major cracks are readily formed.

Finally, a few comments on the behaviour of the $600^{\circ} \mathrm{C}$ uniaxial compression specimens. The microscopic evidence is unambiguous: the rock is heavily cracked. The calculated values from the stress-strain curves may not be a true representation of the elastic moduli $\mathrm{E}$ and $\nu$, but we have used this notation to simplify the presentation of the results and the discussion. Considerably lower strengths and smaller effective moduli were expected for these specimens, but not the negative Poisson's ratios. Similar results were recently reported by Homand-Étienne and Houpert (1982) for a gneiss. Although it seems impossible to come up with a foolproof explanation, we would like to suggest that the heating procedure could somehow cause mineral grains to move radially outwards to a position where a large number of them get stuck together in a fairly open structure. When the specimen was then loaded in uniaxial compression, the applied stress would alter the local stress fields and some grains would be free to move backwards, towards their original positions. This would result in a decrease in the diameter of the specimen.

\section{Conclusions}

Shock heating was found to be a convenient way to produce different densities of microcracks in rock samples without altering the mineralogy of the rock. If any appreciable amount of microcracks is to be produced, it is necessary to carry out the heat-treatment at temperatures above $300^{\circ} \mathrm{C}$.

Our results show that values for most mechanical parameters will decrease with increasing microcrack density. Some of them do, however, display a weak maximum for specimens heat-treated at $100^{\circ} \mathrm{C}$. The uniaxial compressive strength, which is one of the most important parameters in any rock mechanics analysis, showed quite an anomalous behaviour. Specimens preheated to $450^{\circ} \mathrm{C}$ proved to be the strongest in spite of the fact that they contained more microcracks than those heattreated at lower temperatures. This result could be of interest for stability analysis in Rock Mechanics and might also be applicable in earthquake theories. Moreover, the specimens heat-treated at $600^{\circ} \mathrm{C}$ exhibited a rather peculiar mechanical behaviour. There was a steady decrease in their diameters over the first $50 \mathrm{MPa}$ increase in axial stress. The heating procedure is believed to account for this anomaly.

The results presented here indicate that the mechanical data obtained from high temperature experiments on rocks should be analysed with care. Microcracking should always be considered. Small cracks will affect the results if they are present in sufficient amounts. An evident modification of the acoustic properties was also found when the density of microcracks was significantly changed.

Finally, a good correlation was found in most cases between the mechanical parameters and those representing the crack density. The uniaxial compressive strength was in fact the only notable exception. These results have shown that there is an unmistakeable relation between the mechanical properties of the Stripa granite and the density of cracks in the rock. 


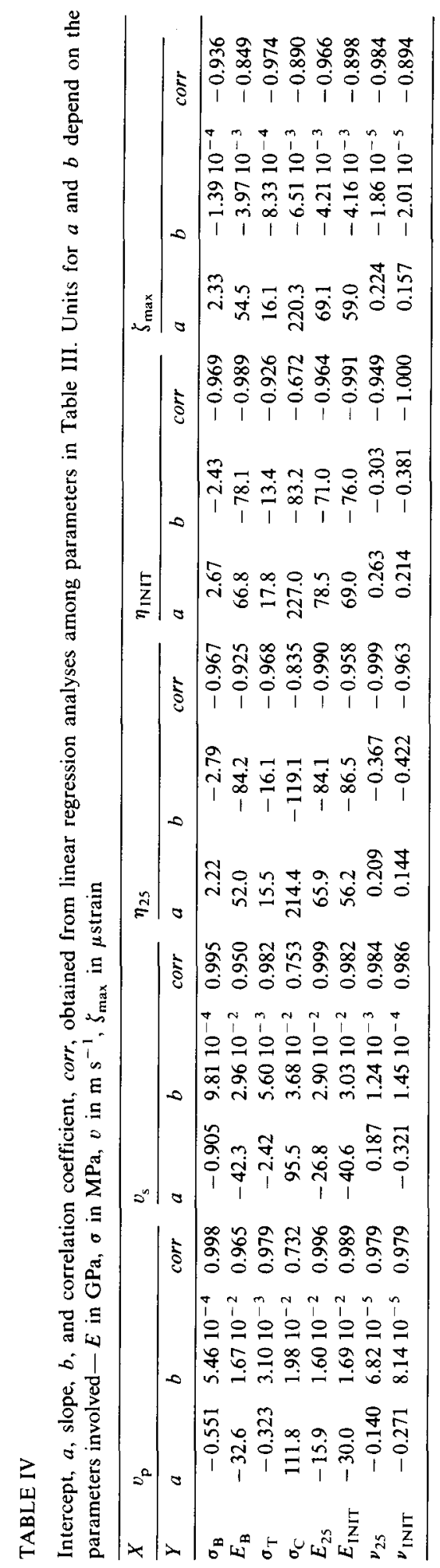




\section{Acknowledgements}

The authors owe a great many thanks to colleagues at the Division of Rock Mechanics for valuable discussions and technical assistance. Thanks are also due to L. Klötz at Brandt Optik $A B$ in Stockholm for good advice and prompt delivery of supplementary microscopic parts at very short notice. This work was financially supported by the Swedish Natural Science Research Council, Contract No. E-EG 3447-117.

\section{References}

Alm, O., Röshoff, K. and Andersson, G., 1983.Identification of thermally induced microcracks in rock materials. In: International Conference on Subsurface Heat Storage; in Theory and Practice. Stockholm, June 6-8, 1983. Proceedings Appendix, part I, pp. 338-342.

Brown, E.T. (Editor), 1981. Rock Characterization Testing and Monitoring: ISRM Suggested Methods. Pergamon Press, Oxford, pp. 113-121.

Budiansky, B. and O'Connell, R.J., 1976. Elastic moduli of a cracked solid. Int. J. Solids Struct., 12: 81-97.

Cooper, H.W. and Simmons, G., 1977. The effect of cracks on the thermal expansion of rocks. Earth Planet. Sci. Lett., 36: 404-412.

Feves, M., Simmons, G. and Siegfried, R.W., 1977. Microcracks in crustal rocks: physical properties. In: J.G. Heacock (Editor), The Earth's Crust: Its Nature and Physical Properties. Geophys. Monogr. Ser., AGU, Washington, 20: 95-117.

Finnie, I., Cooper, G.A. and Berlie, J., 1979. Fracture propagation in rock by transient cooling. Int. J. Rock Mech. Min. Sci. Geomech. Abstr., 16: 11-21.

Homand-Étienne, F. and Houpert, R., 1982. Comportement méchanique d'une roche anisotrope thermiquement fissurée. In: J-P. Boehler (Editor), Comportement Mechnique des Solides Anisotropes. Colloques Internationaux du CNRS No. 295, The Hauge Nijhoff, The Hauge, pp. 265-278.
Johnson, B., Gangi, A.F. and Handin, J., 1978. Thermal cracking of rock subjected to slow, uniform temperature changes. In: Y.S. Kim (Editor), Proc. 19th U.S. Symp. on Rock Mechanics, Stateline, Nevada, May 1-3, pp. 259-267.

Kou, S. and Alm. O., 1985a. An experimental study on the mechanical properties of Stripa granite preheated to different temperatures in the range $20-600^{\circ} \mathrm{C}$. Research Report, Luleå University of Technology, Luleå (in print).

Kou, S. and Alm, O., 1985b. The effect of open cracks on the mechanical properties of rocks (to be published).

Monoto, L., 1982. Digital multi-image analysis: application to the quantification of rock microfractography. IBM J. Res. Develop., 26: 735-745.

Montoto, M., Montoto, L., Röshoff, K. and Leijon, B., 1980. Microfractographic study of heated and non-heated Stripa granite. In: M. Bergman (Editor), Subsurface Space. Proc. Int. Symp. Rockstore 80, Stockholm, June 23-27, Pergamon Press, Oxford, 3: 1357-1368.

Richter, D. and Simmons, G., 1977. Microcracks in crustal rocks: microscopy. In: J.G. Heacock (Editor), The Earth's Crust: Its Nature and Physical Properties. Geophys. Monogr. Ser., AGU, Washington, 20: 149-180.

Siegfried, R.W. and Simmons, G., 1978. Characterization of oriented cracks with differential strain analysis. J. Geophys. Res., 83: 1269-1278.

Simmons, G. and Richter, D., 1976. Microcracks in rocks. In: R.G.J. Strens (Editor), The Physics and Chemistry of Minerals and Rocks. Wiley and Sons, London, pp. 105-137.

Simmons, G. and Wang, H., 1971. Single Crystal Elastic Constants and Calculated Aggregate Properties. The MIT Press, Cambridge, MA.

Simmons, G., Siegfried, R.W. and Feves, M., 1974. Differential strain analysis: a new method for examining cracks in rocks. J. Geophys. Res., 79: 4383-4385.

Sprunt, E.S. and Brace, W.F., 1974. Direct Observation of microcavities in crystalline rocks. Int. J. Rock Mech. Min. Sci. Geomech. Abstr., 11: 139-150.

Sun, Z., 1983. Fracture Mechanics and Tribology of Rocks and Rock Joints. Doctoral thesis 1983:22D, Luleå University of Technology, Luleă, pp. 1-76.

Walsh, J.B. and Brace, W.F., 1966. Cracks and pores in rocks. In: Proc. of the 1st Congr. of the Int. Soc. Rock Mech., Lisboa, Sept 25-Oct 1, 1: 643-646. 